University of Wollongong

Research Online

Faculty of Engineering - Papers (Archive)

Faculty of Engineering and Information

Sciences

$1-4-2004$

\title{
Active Control of Cross Wind Response of 76-Story Tall Building Using a Fuzzy Controller
}

B. Samali

University of Technology Sydney

M. Al-Dawod

University of Technology Sydney

K. C. Kwok

University of Sydney

Fazel Naghdy

University of Wollongong, fazel@uow.edu.au

Follow this and additional works at: https://ro.uow.edu.au/engpapers

Part of the Engineering Commons

https://ro.uow.edu.au/engpapers/341

\section{Recommended Citation}

Samali, B.; Al-Dawod, M.; Kwok, K. C.; and Naghdy, Fazel: Active Control of Cross Wind Response of 76-Story Tall Building Using a Fuzzy Controller 2004.

https://ro.uow.edu.au/engpapers/341

Research Online is the open access institutional repository for the University of Wollongong. For further information contact the UOW Library: research-pubs@uow.edu.au 


\title{
Active Control of Cross Wind Response of 76-Story Tall Building Using a Fuzzy Controller
}

\author{
Bijan Samali ${ }^{1}$; Mohammed Al-Dawod ${ }^{2}$; Kenny C. S. Kwok ${ }^{3}$; and Fazel Naghdy ${ }^{4}$
}

\begin{abstract}
This paper focuses on the benchmark problem application regarding the vibration control of tall buildings under cross wind excitation. The building under consideration is the 76-story, 306-m tall reinforced concrete office tower proposed for the city of Melbourne, Australia. The adopted control scheme consists of an active tuned mass damper (ATMD) where the control action is achieved by a fuzzy logic controller (FLC). The main advantage of the FLC is its inherent robustness and ability to handle any nonlinear behavior of the structure and the fact that its implementation does not require a mathematical model of the structure. This benchmark study is based on specified design constraints for the ATMD to be considered in the design of the proposed control scheme. The performance of the controller has been demonstrated through the uncertainty in stiffness ( +15 and $-15 \%$ variation from initial stiffness) of the building. The results of the simulation show a good performance by the fuzzy controller for all cases tested. Also the results show that the fuzzy controller performance is similar to the linear quadratic Gaussian (LQG) controller, while possessing several advantages over the LQG controller.
\end{abstract}

DOI: 10.1061/(ASCE)0733-9399(2004)130:4(492)

CE Database subject headings: Active control; Wind forces; Fuzzy sets; Buildings, high-rise; Vibration control; Damping.

\section{Introduction}

Environmental loads on tall structures; such as those stemming from wind and earthquake can cause human discomfort, motion sickness, and sometimes endanger structural safety and integrity. Passive, semiactive, and active control schemes are becoming an integral part of the structural systems over the last 2 decades. Active tuned mass damper (ATMD) systems have been a popular area of research for some time and significant progress has been made in this area (Soong and Hanson 1993; Nerves and Krishnan 1995; Battaini et al. 1998a). The main objective of this study is to apply the fuzzy logic controller to the benchmark building defined in the problem definition paper. The building is excited by cross wind loads obtained from the wind tunnel tests at the University of Sydney.

Fuzzy logic algorithm is adopted in this study and validated through computer simulation. Fuzzy logic controller has been investigated for the active control of civil engineering structures

${ }^{1}$ Professor of Structural Engineering, Center for Built Infrastructure Research, Faculty of Engineering, Univ. of Technology Sydney, NSW 2007, Australia. E-mail: bijan.samali@uts.edu.au

${ }^{2}$ Senior Research and Development Officer, Center for Built Infrastructure Research, Faculty of Engineering, Univ. of Technology Sydney, NSW 2007, Australia. E-mail: maldawod@eng.uts.edu.au

${ }^{3}$ Professor, Dept. of Civil Engineering, Univ. of Sydney, NSW 2006, Australia.

${ }^{4}$ Associate Professor, School of Electrical, Computer \& Telecommunication Engineering, Univ. of Wollongong, NSW 2500, Australia. E-mail: fazel.naghdy@uow.edu.au

Note. Associate Editor: Bill F. Spencer Jr. Discussion open until September 1, 2004. Separate discussions must be submitted for individual papers. To extend the closing date by one month, a written request must be filed with the ASCE Managing Editor. The manuscript for this paper was submitted for review and possible publication on March 5, 2003; approved on March 5, 2003. This paper is part of the Journal of Engineering Mechanics, Vol. 130, No. 4, April 1, 2004. CASCE, ISSN 07339399/2004/4-492-498/\$18.00.
(Casciati et al. 1996; Faravelli and Yao 1996; Subramanian et al. 1996; Ayyub et al. 1997; Battaini et al. 1998b; Naghdy et al. 1998; Al Dawod et al. 1999a,b,c) and the current study builds on previous work in this area.

A fuzzy logic controller is robust and capable of handling any nonlinear behavior of the structure. The main advantages in adopting a fuzzy control algorithm are summarized in Battaini et al. (1998a), namely,

1. The uncertainties of input data are treated in a much easier way by fuzzy control theory than by classical control theory. Fuzzy logic, which is the basis of the fuzzy controller, intrinsically accounts for such uncertainties. The implementation of fuzzy controllers makes use of linguistic synthesis and therefore they are not affected by the selection of a specific mathematical model. As a consequence the resulting fuzzy controller possesses inherent robustness.

2. The whole fuzzy controller can be easily implemented in a fuzzy chip, which guarantees immediate reaction time and autonomous power supply.

The knowledge base identifies the actual variables driving the control process. In the specific benchmark problem developed throughout the paper only two variables must be measured and estimated in order to implement the controller. The advantages of employing an intelligent controller against classical controller and the robustness of the fuzzy controller will be highlighted in this paper. The fuzzy controller will be described and the results presented and analyzed.

\section{Structural Model}

The model used in this study is the benchmark building of 76 stories, 306-m tall office tower proposed for the city of Melbourne, Australia (defined in the problem definition paper). The building is slender with a height to width ratio (aspect ratio) of $306 / 42=7.3$; therefore, it is wind sensitive. The total mass of the 


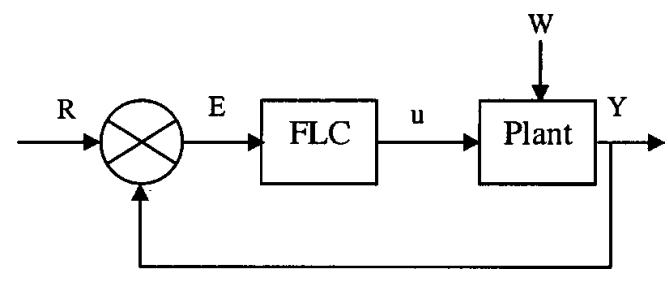

Fig. 1. Fuzzy logic control system

building, including heavy machinery in the plant rooms, is 153,000 t. The 76 story tall building is modeled as a vertical cantilever beam. The first five natural frequencies are $0.16,0.765$, $1.992,3.790$, and $6.395 \mathrm{~Hz}$, respectively. Damping ratios for the first five modes are assumed to be $1 \%$ of critical for the proportional damping matrix. Through a model reduction process, the final model possesses only 23 degrees of freedom for the uncontrolled system. A tuned mass damper (TMD) with an inertial mass of $500 \mathrm{t}$ is installed on the top floor. The damper natural frequency is tuned to $0.16 \mathrm{~Hz}$ and its damping ratio is set at $20 \%$ of critical.

For more details, including performance criteria, refer to the benchmark problem definition paper.

\section{Fuzzy Logic Controller}

Fuzzy logic, introduced by Zadeh (1965), enables the use of linguistic directions as a basis for control. Generally very robust and capable of handling nonlinear systems, fuzzy logic controllers (FLCs) usually require expert knowledge in their construction.

A FLC is incorporated into a closed-loop control system similar to conventional controllers as shown in Fig. 1, where, $R$ is the reference input; $E$ the input signal (error); $u$ the output control force; $W$ is the wind excitation, and $Y$ the response after control. The most widely used fuzzy control inference $M$ is the "if-then" rule, which can be written as follows when two input data are used in their antecedent parts (Wang 1994)

$M^{i}: \quad$ if $X_{1}=A_{i}$ and $X_{2}=B_{i}$ then $Y=C_{i}$

where $i=$ number of control rules; $X_{1}$ and $X_{2}=$ variables of the antecedent parts; $Y=$ variable of the sequent part; and $A_{i}, B_{i}$, and $C_{i}=$ fuzzy variables. The basic structure of a typical FLC is illustrated in Fig. 2. Various components of this controller are defined as follows:

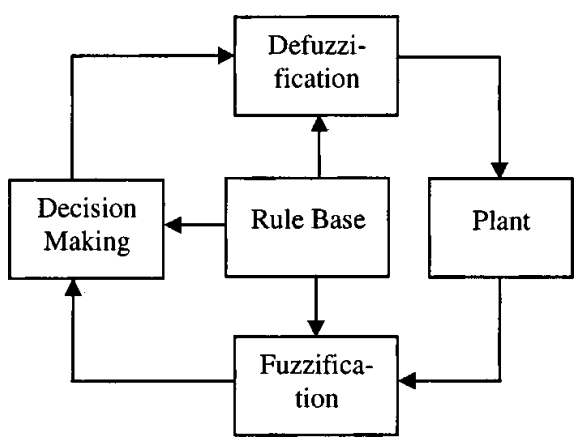

Fig. 2. Basic structure of fuzzy logic controller

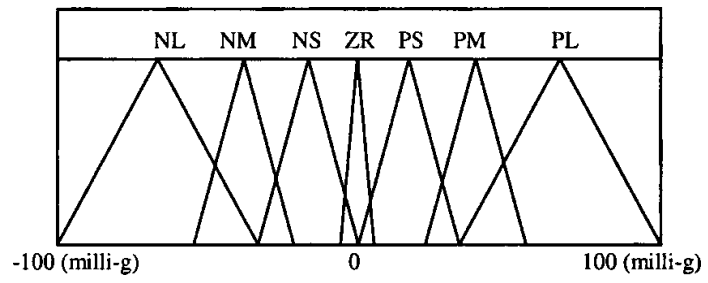

Fig. 3. Membership function for acceleration at L50 and L76

\section{Fuzzification}

This unit maps the measured inputs, which may be in the form of crisp values, into fuzzy linguistic values using fuzzy reasoning mechanism.

\section{Rule Base}

This is a collection of the expert control rules (knowledge) needed to achieve the control goal.

\section{Decision Making}

This unit is the fuzzy reasoning mechanism, which performs various fuzzy logic operations to infer the control action for a given fuzzy input.

\section{Defuzzification}

The inferred fuzzy control action is converted into required crisp control value in this unit.

In this paper, the preliminary design of the controller will couple the Larsen's maximum product rule (Yan et al. 1994), to combine the membership values for each rule, with the center of gravity defuzzification scheme, to obtain the output crisp value.

\section{Fuzzy Controller Design}

The fuzzy controller uses crisp data directly from a number of sensors; these data are then converted into linguistic or fuzzy membership functions through the fuzzification process. The number of sensors used in the system is dependent on the number of input variables used in the controller.

The controller is designed using two input variables, each one having seven membership functions, and one output variable with 11 membership functions. The membership functions chosen for the input and output variables are triangular shaped as illustrated in Figs. 3 and 4, respectively. The fuzzy variables used to define

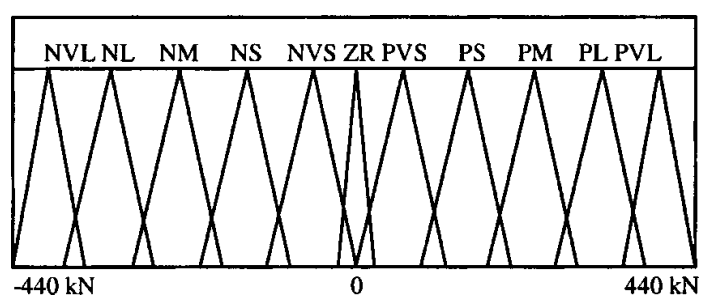

Fig. 4. Membership function for control force 
Table 1. Fuzzy Variables

\begin{tabular}{ll}
\hline Variable & \multicolumn{1}{c}{ Definition } \\
\hline PVL & Positive and very large \\
PL & Positive and large \\
PM & Positive and medium \\
PS & Positive and small \\
PVS & Positive and very small \\
ZR & Zero \\
NVS & Negative and very small \\
NS & Negative and small \\
NM & Negative and medium \\
NL & Negative and large \\
NVL & Negative and very large \\
\hline
\end{tabular}

the fuzzy space are described in Table 1. The self-organizing fuzzy logic controller is used to find the final fuzzy associative memory as shown in Table 2 .

The writers suggest using the acceleration of floors 50 and 76 as feedback variables for the fuzzy controller design because the response of the building is larger in the top floors compared to lower ones. The aim of using two input variables for the fuzzy controller is to show the performance of the fuzzy approach in the control problem. The small number of feedback variables means the use of fewer sensors; thus a simplification of the control system with advantages in terms of reliability and costs.

The control schemes provided in the benchmark study is used in the simulation and a deterministic context has been selected. The fuzzy controller is implemented into the SIMULINK program (see Fig. 5) using an integration time step of $0.001 \mathrm{~s}$ and the control signal is computed every $0.001 \mathrm{~s}$.
Table 2. Fuzzy Associative Memory of Fuzzy Controller

\begin{tabular}{lccccccc}
\hline $\begin{array}{l}\text { Acceleration } \\
\text { of 76th floor }\end{array}$ & \multicolumn{7}{c}{ Acceleration of 50th floor } \\
\cline { 2 - 7 }$u$ & NL & NM & NS & ZR & PS & PM & PL \\
\hline NL & PVL & PVL & PL & PVS & ZR & ZR & ZR \\
NM & PL & PL & PM & PVS & ZR & ZR & ZR \\
NS & ZR & NVS & PM & PS & PVS & ZR & ZR \\
ZR & ZR & ZR & NVS & ZR & PVS & ZR & ZR \\
PS & ZR & ZR & NVS & NS & NM & PVS & ZR \\
PM & ZR & ZR & ZR & NVS & NM & NL & NL \\
PL & ZR & ZR & ZR & NVS & NL & NVL & NVL \\
\hline
\end{tabular}

Note: Definitions given in Table 1.

\section{Control Performance}

The performance of the fuzzy controller is checked according to the evaluation criteria specified for the benchmark building $\left(J_{1}-J_{12}\right)$, in the problem definition paper. Table 3 shows the results of peak and root mean square (RMS) uncontrolled and the passively controlled response (TMD) of the benchmark building. Tables 4, 5, and 6 show the results of the simulation using the fuzzy and linear quadratic Gaussian (LQG) controllers in terms of peak displacement and acceleration for the three cases of nominal building, the building with $15 \%$ higher stiffness, and the building with $15 \%$ lower stiffness, respectively. Tables 7, 8, and 9 show the results of the simulation using the fuzzy and LQG controllers in terms of RMS displacement and acceleration for the same cases, respectively.

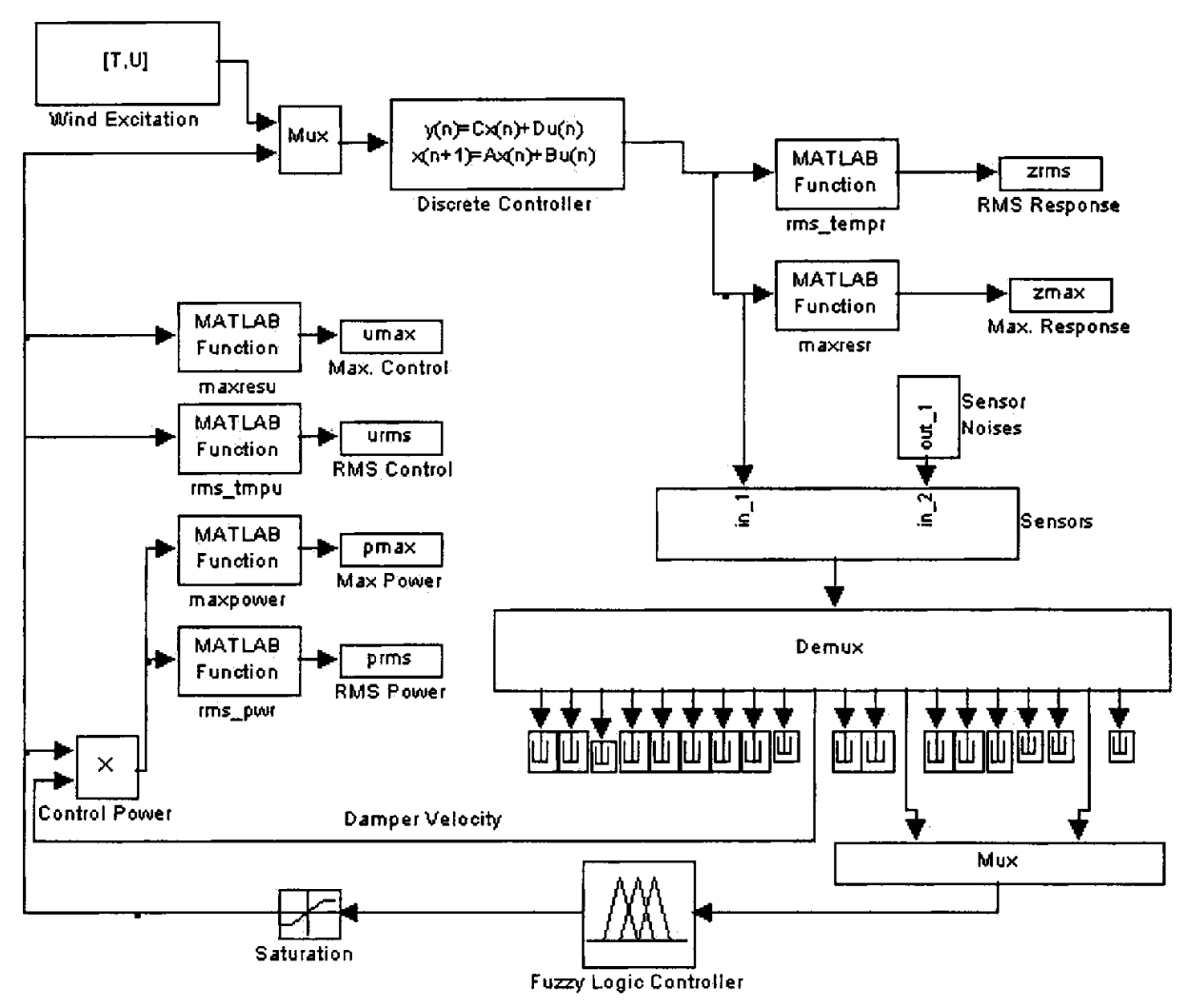

Fig. 5. SIMULINK model of building with fuzzy controller 
Table 3. Root Mean Square (RMS) and Peak Response of 76-Story Building [No Control and Tuned Mass Damper (TMD)]

\begin{tabular}{|c|c|c|c|c|c|c|c|c|}
\hline \multirow[b]{2}{*}{ Floor no. } & \multicolumn{2}{|c|}{ RMS response no control } & \multicolumn{2}{|c|}{ RMS response TMD } & \multicolumn{2}{|c|}{ Peak response no control } & \multicolumn{2}{|c|}{ Peak response TMD } \\
\hline & $\begin{array}{l}\text { Displacement } \\
(\mathrm{mm})\end{array}$ & $\begin{array}{l}\text { Acceleration } \\
(\mathrm{m} g)\end{array}$ & $\begin{array}{l}\text { Displacement } \\
\quad(\mathrm{mm})\end{array}$ & $\begin{array}{l}\text { Acceleration } \\
(\mathrm{m} g)\end{array}$ & $\begin{array}{l}\text { Displacement } \\
\quad(\mathrm{mm})\end{array}$ & $\begin{array}{l}\text { Acceleration } \\
(\mathrm{m} g)\end{array}$ & $\begin{array}{l}\text { Displacement } \\
(\mathrm{mm})\end{array}$ & $\begin{array}{l}\text { Acceleration } \\
(\mathrm{m} g)\end{array}$ \\
\hline 1 & 0.2 & 0.1 & 0.1 & 0.1 & 0.5 & 0.2 & 0.4 & 0.2 \\
\hline 30 & 21.5 & 2.0 & 14.8 & 1.2 & 68.4 & 7.1 & 56.0 & 4.7 \\
\hline 50 & 52.2 & 4.8 & 35.7 & 2.8 & 165.9 & 15.0 & 133.4 & 9.3 \\
\hline 55 & 61.1 & 5.6 & 41.7 & 3.3 & 194.1 & 17.5 & 155.4 & 10.7 \\
\hline 60 & 70.2 & 6.4 & 47.9 & 3.7 & 223.4 & 20.0 & 178.0 & 12.7 \\
\hline 65 & 79.7 & 7.3 & 54.3 & 4.3 & 253.5 & 22.6 & 201.0 & 14.7 \\
\hline 70 & 89.2 & 8.2 & 60.8 & 4.8 & 284.1 & 26.0 & 224.3 & 16.8 \\
\hline 75 & 99.2 & 9.1 & 67.5 & 5.4 & 315.9 & 30.3 & 248.4 & 19.8 \\
\hline 76 & 101.4 & 9.4 & 69.0 & 5.5 & 323.0 & 31.2 & 253.8 & 20.5 \\
\hline $\mathrm{md}$ & - & - & 127.6 & 13.9 & - & - & 426.0 & 46.2 \\
\hline
\end{tabular}

Table 4. Peak Response of 76-Story Nominal Benchmark Building Using Fuzzy and Linear Quadratic Gaussian (LQG) Controllers

\begin{tabular}{lccccc}
\hline & \multicolumn{2}{c}{$\begin{array}{c}\text { Fuzzy controller, } \\
\text { peak control force=113.9 kN }\end{array}$} & & \multicolumn{2}{c}{$\begin{array}{c}\text { LQG controller, } \\
\text { peak control force=118.2 kN }\end{array}$} \\
\cline { 2 - 3 } \cline { 5 - 6 } Floor no. & $\begin{array}{c}\text { Displacement } \\
(\mathrm{mm})\end{array}$ & $\begin{array}{c}\text { Acceleration } \\
(\mathrm{m} g)\end{array}$ & & $\begin{array}{c}\text { Displacement } \\
(\mathrm{mm})\end{array}$ & $\begin{array}{c}\text { Acceleration } \\
(\mathrm{m} g)\end{array}$ \\
\hline 1 & 0.4 & 0.2 & & 0.4 & 0.2 \\
30 & 50.7 & 3.5 & & 51.4 & 3.4 \\
50 & 120.4 & 6.6 & & 122.2 & 6.7 \\
55 & 140.1 & 8.0 & & 142.2 & 8.1 \\
60 & 160.3 & 9.0 & & 162.7 & 8.9 \\
65 & 180.9 & 10.0 & & 183.7 & 10.1 \\
70 & 201.7 & 10.3 & & 204.8 & 10.7 \\
75 & 223.1 & 11.0 & & 226.7 & 11.6 \\
76 & 227.9 & 15.4 & 231.6 & 15.9 \\
$\mathrm{md}$ & 726.3 & 72.1 & 742.9 & 72.7 \\
\hline
\end{tabular}

Table 5. Peak Response of 76-Story Building (with $+15 \%$ ) Stiffness Using Fuzzy and Linear Quadratic Gaussian (LQG) Controllers

\begin{tabular}{lccccc}
\hline & \multicolumn{2}{c}{$\begin{array}{c}\text { Fuzzy controller, } \\
\text { peak control force=110.9 kN }\end{array}$} & & \multicolumn{2}{c}{$\begin{array}{c}\text { LQG controller, } \\
\text { peak control force=105.6 kN }\end{array}$} \\
\cline { 6 - 6 } \cline { 5 - 6 } Floor no. & $\begin{array}{c}\text { Displacement } \\
(\mathrm{mm})\end{array}$ & $\begin{array}{c}\text { Acceleration } \\
(\mathrm{m} g)\end{array}$ & $\begin{array}{c}\text { Displacement } \\
(\mathrm{mm})\end{array}$ & $\begin{array}{c}\text { Acceleration } \\
(\mathrm{m} g)\end{array}$ \\
\hline 1 & 0.3 & 0.2 & & 0.3 & 0.2 \\
30 & 43.7 & 3.4 & & 43.5 & 3.4 \\
50 & 103.9 & 6.3 & & 103.5 & 6.6 \\
55 & 121.0 & 7.8 & & 120.4 & 8.0 \\
60 & 138.5 & 8.7 & & 137.8 & 9.1 \\
65 & 156.3 & 10.0 & & 155.5 & 10.1 \\
70 & 174.3 & 10.6 & 173.4 & 11.6 \\
75 & 192.9 & 11.3 & & 191.8 & 12.5 \\
76 & 197.1 & 16.1 & 196.0 & 15.9 \\
$\mathrm{md}$ & 606.6 & 70.6 & 598.3 & 60.9 \\
\hline
\end{tabular}

As observed from the results in Tables 4-9, the performance of the fuzzy controller is similar and in some cases better than the LQG controller. These tables also show that both controllers perform better when stiffness is increased by $15 \%$ but their performance is not as good when stiffness is decreased by $15 \%$. Table 10 shows the comparison of the performance indices $J_{1}-J_{12}$ in-
Table 6. Peak Response of 76-Story Building (with -15\%) Stiffness Using Fuzzy and Linear Quadratic Gaussian (LQG) Controllers

\begin{tabular}{lccccc}
\hline & $\begin{array}{c}\text { Fuzzy controller, } \\
\text { peak control force }=135.7 \mathrm{kN}\end{array}$ & & \multicolumn{2}{c}{$\begin{array}{c}\text { LQG controller, } \\
\text { peak control force=164.3 kN }\end{array}$} \\
\cline { 2 - 3 } \cline { 5 - 6 } Floor no. & $\begin{array}{c}\text { Displacement } \\
(\mathrm{mm})\end{array}$ & $\begin{array}{c}\text { Acceleration } \\
(\mathrm{m} g)\end{array}$ & & $\begin{array}{c}\text { isplacement } \\
(\mathrm{mm})\end{array}$ & $\begin{array}{c}\text { Acceleration } \\
(\mathrm{m} g)\end{array}$ \\
\hline 1 & 0.4 & 0.2 & 0.4 & 0.2 \\
30 & 55.5 & 3.7 & & 55.4 & 3.6 \\
50 & 131.6 & 7.5 & & 131.2 & 7.9 \\
55 & 153.0 & 9.5 & & 152.7 & 9.9 \\
60 & 175.0 & 10.8 & & 174.7 & 11.1 \\
65 & 197.4 & 12.3 & & 197.1 & 12.6 \\
70 & 220.1 & 13.5 & & 220.0 & 14.0 \\
75 & 243.6 & 12.9 & & 243.4 & 14.8 \\
76 & 248.9 & 20.1 & 248.7 & 18.8 \\
md & 841.7 & 80.8 & 916.0 & 79.1 \\
\hline
\end{tabular}

Table 7. Root Mean Square (RMS) Response of 76-Story Nominal Benchmark Building Using Fuzzy and Linear Quadratic Gaussian (LQG) Controllers

\begin{tabular}{lccccc}
\hline & $\begin{array}{c}\text { Fuzzy controller, } \\
\text { RMS control force }=37.2 \mathrm{kN}\end{array}$ & & \multicolumn{2}{c}{$\begin{array}{c}\text { LQG controller, } \\
\text { RMS control force=34.1 kN }\end{array}$} \\
\cline { 2 - 3 } \cline { 5 - 6 } Floor no. & $\begin{array}{c}\text { Displacement } \\
(\mathrm{mm})\end{array}$ & $\begin{array}{c}\text { Acceleration } \\
(\mathrm{m} g)\end{array}$ & & $\begin{array}{c}\text { Displacement } \\
(\mathrm{mm})\end{array}$ & $\begin{array}{c}\text { Acceleration } \\
(\mathrm{m} g)\end{array}$ \\
\hline 1 & 0.1 & 0.1 & & 0.1 & 0.1 \\
30 & 12.1 & 0.9 & & 12.6 & 0.9 \\
50 & 29.2 & 1.9 & & 30.4 & 2.0 \\
55 & 34.1 & 2.2 & & 35.5 & 2.4 \\
60 & 39.1 & 2.6 & & 40.8 & 2.8 \\
65 & 44.3 & 2.9 & & 46.2 & 3.2 \\
70 & 49.5 & 3.1 & & 51.7 & 3.4 \\
75 & 55.0 & 2.9 & & 57.4 & 3.3 \\
76 & 56.2 & 4.6 & & 58.6 & 4.7 \\
md & 244.3 & 24.7 & 233.0 & 22.4 \\
\hline
\end{tabular}

cluding the actuator actions between the fuzzy and the LQG controllers.

The results of the simulation show that the fuzzy controller can satisfy the design requirements of the benchmark problem. The constraints on the actuator requirements (RMS control force $\leqslant 100 \mathrm{kN}$, RMS actuator stroke $\leqslant 300 \mathrm{~mm}$, peak control 
Table 8. Root Mean Square (RMS) Response of 76-Story Building (with $+15 \%$ ) Stiffness Using Fuzzy and Linear Quadratic Gaussian (LQG) Controllers

\begin{tabular}{lccccc}
\hline & $\begin{array}{c}\text { Fuzzy controller, } \\
\text { RMS control force }=45.9 \mathrm{kN}\end{array}$ & & \multicolumn{2}{c}{$\begin{array}{c}\text { LQ controller, } \\
\text { RMS control force=28.3 kN }\end{array}$} \\
\cline { 2 - 3 } \cline { 5 - 6 } Floor no. & $\begin{array}{c}\text { Displacement } \\
(\mathrm{mm})\end{array}$ & $\begin{array}{c}\text { Acceleration } \\
(\mathrm{m} g)\end{array}$ & $\begin{array}{c}\text { Displacement } \\
(\mathrm{mm})\end{array}$ & $\begin{array}{c}\text { Acceleration } \\
(\mathrm{m} g)\end{array}$ \\
\hline 1 & 0.1 & 0.1 & & 0.1 & 0.1 \\
30 & 10.2 & 0.9 & & 10.7 & 0.9 \\
50 & 24.5 & 1.8 & & 25.7 & 2.0 \\
55 & 28.6 & 2.1 & & 30.0 & 2.4 \\
60 & 32.9 & 2.5 & & 34.4 & 2.7 \\
65 & 37.2 & 2.8 & & 39.0 & 3.1 \\
70 & 41.6 & 2.9 & & 43.6 & 3.3 \\
75 & 46.2 & 2.8 & & 48.3 & 3.3 \\
76 & 47.2 & 4.5 & 49.4 & 4.5 \\
md & 210.0 & 23.3 & & 183.7 & 19.2 \\
\hline
\end{tabular}

force $\leqslant 300 \mathrm{kN}$, and peak actuator stroke $\leqslant 950 \mathrm{~mm}$ ), are all satisfied for all cases using the fuzzy controller. Also, the maximum allowable floor acceleration of 15 milli-g (or a RMS value of 5 milli-g) is satisfied. In comparison with the closed-loop response of the nominal structure, the displacement response, actuator stroke, active control force, and control power for the $+15 \%$ building with fuzzy controller reduce by $16,14.1,3.4$, and $12.7 \%$, respectively. On the other hand, for the LQG controller the corresponding reductions are $15.7,20.2,17.0$, and $29.4 \%$, respectively. For the $-15 \%$ building with fuzzy controller, the displacement response, actuator storke, active control force, and control power increase by $24.4,8.1,6.8$, and $5.9 \%$, respectively, and increase by $23,19.3,30.1$, and $38.5 \%$, respectively, when using the LQG controller. The big advantage of using fuzzy controller over the LQG controller is the power consumption as witnessed by much smaller $J_{6}$ index. In this study the RMS of control power for fuzzy controller is less than half of that for the LQG controller and is almost constant for all three cases with varying stiffness.
Table 9. Root Mean Square (RMS) Response of 76-Story Building (with $-15 \%$ ) Stiffness Using Fuzzy and Linear Quadratic Gaussian (LQG) Controllers

\begin{tabular}{lccccc}
\hline & $\begin{array}{c}\text { Fuzzy controller, } \\
\text { RMS control force }=39.7 \mathrm{kN}\end{array}$ & & \multicolumn{2}{c}{$\begin{array}{c}\text { LQG controller, } \\
\text { RMS control force }=44.3 \mathrm{kN}\end{array}$} \\
\cline { 2 - 3 } \cline { 5 - 6 } Floor no. & $\begin{array}{c}\text { Displacement } \\
(\mathrm{mm})\end{array}$ & $\begin{array}{c}\text { Acceleration } \\
(\mathrm{m} g)\end{array}$ & & $\begin{array}{c}\text { Displacement } \\
(\mathrm{mm})\end{array}$ & $\begin{array}{c}\text { Acceleration } \\
(\mathrm{m} g)\end{array}$ \\
\hline 1 & 0.1 & 0.1 & & 0.1 & 0.1 \\
30 & 15.0 & 1.0 & & 15.5 & 1.0 \\
50 & 36.2 & 2.0 & & 37.3 & 2.1 \\
55 & 42.3 & 2.4 & & 43.6 & 2.6 \\
60 & 48.6 & 2.8 & & 50.1 & 3.0 \\
65 & 55.0 & 3.2 & & 56.8 & 3.3 \\
70 & 61.6 & 3.3 & & 63.5 & 3.5 \\
75 & 68.4 & 3.1 & & 70.5 & 3.4 \\
76 & 69.9 & 5.0 & & 72.1 & 5.1 \\
$\mathrm{md}$ & 264.3 & 24.3 & 274.7 & 24.3 \\
\hline
\end{tabular}

This is not, however, the case for the LQG controller and the RMS of control power varies in the range of $20-40 \mathrm{kN} \mathrm{m}$.

Another aspect of the fuzzy controller robustness is the ability to control the system with different time steps (for both integration and computation of control signal). Table 11 shows the performance of the fuzzy controller when the time step changes from 0.001 to $0.01 \mathrm{~s}$, with almost identical results. However, the LQG controller becomes unstable when the time step changes from the 0.001 to $0.01 \mathrm{~s}$. Therefore, the fuzzy controller has more flexibility and robustness not only under system uncertainty but also computationally with respect to varying sample time. Furthermore, in the implementation of the fuzzy controller, only two sensors are used, compared to three sensors used by LQG controller, and this made the system simpler with advantages in terms of reliability and cost.

In this comparison, the fuzzy controller performance is fairly similar to the LQG controller in terms of the building response, the active control force required, and the stroke of the actuator,

Table 10. Evaluation Criteria Comparison: Fuzzy Controller versus Linear Quadratic Gaussian (LQG) Controller

\begin{tabular}{|c|c|c|c|c|c|c|}
\hline \multirow[b]{2}{*}{ Evaluation criteria } & \multicolumn{3}{|c|}{ Fuzzy controller } & \multicolumn{3}{|c|}{ LQG controller } \\
\hline & $+0 \%$ stiffness & $+15 \%$ stiffness & $-15 \%$ stiffness & $+0 \%$ stiffness & $+15 \%$ stiffness & $-15 \%$ stiffness \\
\hline$J_{1}$ & 0.334 & 0.322 & 0.366 & 0.369 & 0.365 & 0.388 \\
\hline$J_{2}$ & 0.380 & 0.365 & 0.414 & 0.417 & 0.409 & 0.438 \\
\hline$J_{3}$ & 0.554 & 0.465 & 0.689 & 0.578 & 0.487 & 0.711 \\
\hline$J_{4}$ & 0.556 & 0.467 & 0.691 & 0.580 & 0.489 & 0.713 \\
\hline$J_{5}$ & 2.410 & 2.072 & 2.608 & 2.272 & 1.812 & 2.710 \\
\hline$J_{6}$ & 13.853 & 12.086 & 14.666 & 29.38 & 20.74 & 40.69 \\
\hline$J_{7}$ & 0.363 & 0.372 & 0.444 & 0.381 & 0.411 & 0.488 \\
\hline$J_{8}$ & 0.426 & 0.421 & 0.512 & 0.432 & 0.443 & 0.539 \\
\hline$J_{9}$ & 0.706 & 0.610 & 0.770 & 0.717 & 0.607 & 0.770 \\
\hline$J_{10}$ & 0.714 & 0.617 & 0.780 & 0.725 & 0.614 & 0.779 \\
\hline$J_{11}$ & 2.249 & 1.878 & 2.606 & 2.300 & 1.852 & 2.836 \\
\hline$J_{12}$ & 65.198 & 64.892 & 91.318 & 71.96 & 52.69 & 118.33 \\
\hline Root mean square control force $(\mathrm{kN})$ & 37.18 & 35.92 & 39.71 & 34.07 & 28.29 & 44.33 \\
\hline Root mean square actuator stroke (mm) & 244.4 & 210.0 & 264.3 & 230.3 & 183.7 & 274.7 \\
\hline Root mean square control power $(\mathrm{kN} \mathrm{m})$ & 13.85 & 12.09 & 14.67 & 29.38 & 20.74 & 40.69 \\
\hline Peak control force $(\mathrm{kN})$ & 113.88 & 110.9 & 135.71 & 118.24 & 105.58 & 164.33 \\
\hline Peak actuator stroke (mm) & 726.3 & 606.6 & 841.7 & 742.9 & 598.2 & 916.0 \\
\hline Peak control power $(\mathrm{kN} \mathrm{m})$ & 65.20 & 64.89 & 91.32 & 71.96 & 52.69 & 118.3 \\
\hline
\end{tabular}


Table 11. Evaluation Criteria for Fuzzy Controller with Different Time Steps

\begin{tabular}{|c|c|c|c|c|c|c|}
\hline \multirow[b]{2}{*}{ Evaluation criteria } & \multicolumn{3}{|c|}{ Fuzzy controller, Time step $=0.001$} & \multicolumn{3}{|c|}{ Fuzzy controller, Time step $=0.001$} \\
\hline & $+0 \%$ stiffness & $+15 \%$ stiffness & $-15 \%$ stiffness & $+0 \%$ stiffness & $+15 \%$ stiffness & $-15 \%$ stiffness \\
\hline$J_{1}$ & 0.334 & 0.322 & 0.366 & 0.334 & 0.322 & 0.366 \\
\hline$J_{2}$ & 0.380 & 0.365 & 0.414 & 0.379 & 0.365 & 0.414 \\
\hline$J_{3}$ & 0.554 & 0.465 & 0.689 & 0.554 & 0.465 & 0.689 \\
\hline$J_{4}$ & 0.556 & 0.467 & 0.691 & 0.556 & 0.467 & 0.691 \\
\hline$J_{5}$ & 2.410 & 2.072 & 2.608 & 2.411 & 2.072 & 2.608 \\
\hline$J_{6}$ & 13.853 & 12.086 & 14.666 & 13.849 & 12.080 & 14.661 \\
\hline$J_{7}$ & 0.363 & 0.372 & 0.444 & 0.364 & 0.371 & 0.442 \\
\hline$J_{8}$ & 0.426 & 0.421 & 0.512 & 0.425 & 0.421 & 0.511 \\
\hline$J_{9}$ & 0.706 & 0.610 & 0.770 & 0.706 & 0.610 & 0.770 \\
\hline$J_{10}$ & 0.714 & 0.617 & 0.780 & 0.714 & 0.617 & 0.780 \\
\hline$J_{11}$ & 2.249 & 1.878 & 2.606 & 2.249 & 1.878 & 2.606 \\
\hline$J_{12}$ & 65.198 & 64.892 & 91.318 & 63.363 & 63.683 & 90.672 \\
\hline Root mean square control force $(\mathrm{kN})$ & 37.18 & 35.92 & 39.71 & 37.13 & 35.86 & 39.66 \\
\hline Root mean square actuator stroke (mm) & 244.4 & 210.0 & 264.3 & 244.4 & 210.0 & 264.4 \\
\hline Root mean square control power $(\mathrm{kN} \mathrm{m})$ & 13.85 & 12.09 & 14.67 & 13.84 & 12.08 & 14.66 \\
\hline Peak control force $(\mathrm{kN})$ & 113.88 & 110.91 & 135.71 & 112.25 & 107.23 & 134.39 \\
\hline Peak actuator stroke $(\mathrm{mm})$ & 726.3 & 606.6 & 841.7 & 726.3 & 606.5 & 841.8 \\
\hline Peak control power $(\mathrm{kN} \mathrm{m})$ & 65.20 & 64.89 & 91.32 & 63.36 & 63.68 & 90.67 \\
\hline
\end{tabular}

but is much better with respect to the number of sensors required for the system and the required control power. These results show that the adopted fuzzy controller has great potential for active structural control.

\section{Stability of Fuzzy Controller}

Often the designers are concerned about the stability of the fuzzy controller system because the fuzzy controller does not have a mathematical model to be used to check its stability. Up to now there has been no general solution to this problem, but there is a number of stability analysis criteria proposed in the literature, (Yan et al. 1994). One of the proposed methods to ensure stability is the phase plane trajectory, which is a technique to reflect graphically the dynamic properties of a control system in a phase plane.

The control stability can be checked through the ability of the controlled system to return to rest conditions following oscillations caused by an external disturbance. In practice one runs the dynamic simulation, selects the state variable that seems to show the most severe response, and then runs the controlled system using the extreme values of the selected state variables. The test

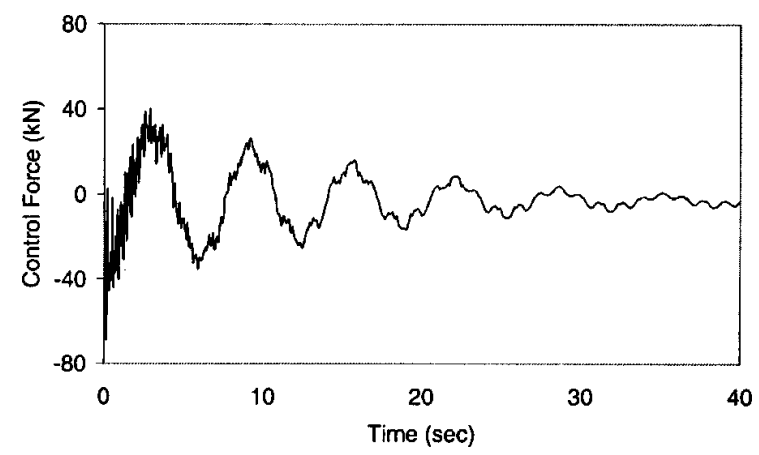

Fig. 6. Fuzzy controller stability test in terms of control force consists of checking the ability of the controller to reduce the response and to drive the system to the rest condition after the initial transient phase (Casciati 1997). The stability tests are performed considering the system with particular initial conditions on the state vector $x$ and checking the ability of the controller to reach equilibrium after the initial transient phase. Figs. 6-8 show the stability tests of the fuzzy controller in terms of the control force, control power, and the acceleration response, respectively. These figures show the ability of the fuzzy controller to drive the system to the rest position after an initial excitation (free vibration) and converge to zero, which means the system is stable.

\section{Conclusions}

In this paper, the studies on the benchmark building defined in the problem definition paper, regarding the vibration control of the building under cross wind excitation, was reported. The fuzzy logic controller for structural control application was adopted to drive the ATMD to control the system. The advantages of employing an intelligent controller against classical controller have been highlighted.

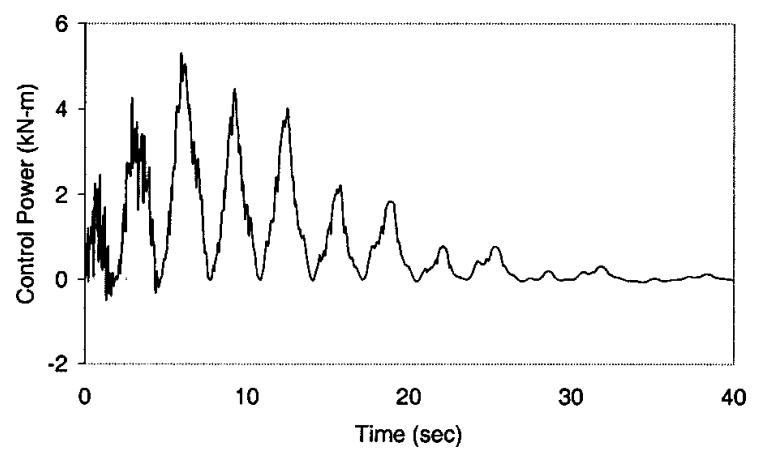

Fig. 7. Fuzzy controller stability test in terms of control power 


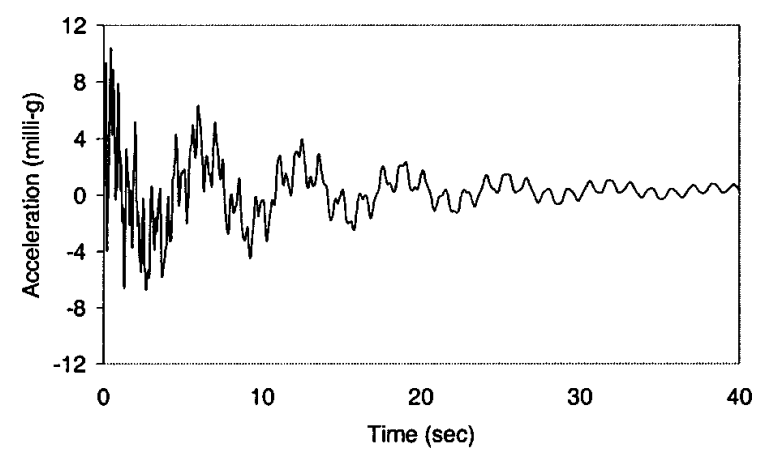

Fig. 8. Fuzzy controller stability test in terms of acceleration response

The results show that, the fuzzy controller performs fairly similarly to the LQG controller in terms of the building response, the active control force required, and the stroke of the actuator, but performs much better in terms of required control power and also requires fewer number of sensors for the system. These results show that the adopted fuzzy controller has great potential in active structural control.

In the next stage of the work, the adopted fuzzy logic controller will be tested experimentally by using a shake table and the benchmark model of 5 stories at the Univ. of Technology, Sydney (Samali 1999).

\section{Acknowledgments}

The writers would like to acknowledge the financial contributions received from the Australian Research Council under Large Grant Scheme (No. A89773) and from the University of Technology, Sydney through Center for Built Infrastructure Research in support of this project.

\section{References}

Al-Dawod, M., Faghdy, F., Samali, B., and Kwok, K. (1999a). "Active control of wind excited structures using fuzzy logic." Proc., 8th IEEE Int. Conf. on Fuzzy Systems, Seoul, Korea, 1-72-1-77.
Al-Dawod, M., Samali, B., Naghdy, F., and Kwok, K. (1999b). "Application of a robust fuzzy controller to a wind excited structure." Proc., Asia-Pacific Vibration Control'99, Singapore, 812-887.

Al-Dawod, M., Samali, B., Naghdy, F., and Kwok, K. (1999c). “Application of fuzzy controller to a $2 \mathrm{DOF}$ wind excited structures." Proc., Int. Conf. on Application of Model Analysis '99, Gold Coast, Australia, Session 8.

Ayyub, B., Guran, A., and Haldar, A., eds. (1997). Uncertainty modeling in vibration, control and fuzzy analysis of structural system, Singapore, River Edge, N.J.

Battaini, M., Casciati, F., and Faravelli, L. (1998a). "Control algorithm and sensor location." Proc., 2nd World Conf. on Structural Control, Kyoto, Japan, 1391-1398.

Battaini, M., Casciati, F., and Faravelli, L. (1998b). "Fuzzy control of structural vibration, an active system driven by a fuzzy controller." $J$. Earthquake Eng. Struct. Dyn., 27(11), 1267-1276.

Casciati, F. (1997). "Checking the stability of a fuzzy controller for nonlinear structures.” J. Microcomput. Civ. Eng., 12, 205-215.

Casciati, F., Faravelli, L., and Yao, T. (1996). "The effect of nonlinearities upon fuzzy structural control." J. Nonlin. Dyn., 11, 171-187.

Faravelli, L., and Yao, T. (1996). "Use of adaptive networks in fuzzy control of civil engineering structures." J. Microcomput. Civ. Eng., 12, 67-76.

Naghdy, F., Samali, B., Kwok, K., and Lam, V. (1998). "Intelligent active control of wind excited structures." Proc., 4th Int. Conf. on Motion and Vibration Control, Zurich, Switzerland, 1195-1199.

Nerves, C., and Krishnan, R. (1995). "Active control strategies for tall civil structures." J. IECON, IEEE, Los Alamitos, Calif., 2, 962-967.

Samali, B. (1999). "System identification of a five story benchmark model using modal analysis." Proc., Asia-Pacific Vibration Conf. '99, Singapore, 701-706.

Soong, T. T., and Hanson, R. (1993). "Recent developments in active and hybrid control research in the U.S." Proc., Int. Workshop on Structural Control, 483-490.

Subramanian, R., Reinhorn, A., Nagacajaiah, S., and Nagacajaiah, M. R. (1996). "Hybrid control of structures using fuzzy logic." J. Microcomput. Civ. Eng., 11, 1-18.

Wang, L.-X. (1994). Adaptive fuzzy systems and control: Design and stability analysis, PTR Prentice Hall, Englewood Cliffs, N.J.

Yan, J., Ryan, M., and Power, J. (1994). Using fuzzy logic: Towards intelligent systems, Prentice Hall, New York.

Zadeh, L. A. (1965). "Fuzzy set.” J. Info. Control, 338-353. 